\title{
IMPUTASI MISSING DATA DENGAN K-NEAREST NEIGHBOR DANALGORITMA GENETIKA
}

\author{
Ucik Mawarsari \\ Badan Pusat Statistik \\ J1. Dr. Sutomo 6-8 Jakarta, ucik@bps.go.id
}

\begin{abstract}
ABSTRAK
Permasalahan yang sering muncul pada suatu data adalah adanya ketidaklengkapan data pada suatu variabel atau sering disebut dengan missing data. Untuk menangani missing data, salah satu cara yang dapat digunakan adalah dengan melakukan imputasi. Salah satu metode imputasi yang cukup sederhana adalah $k$-Nearest Neighbor $(\mathrm{kNN})$. Namun salah satu kelemahan metode kNN adalah permasalahan dalam pemilihan nilai $k$ karena pemilihan nilai $k$ yang kurang tepat dapat menurunkan kinerja kNN. Penelitian ini mengkaji metode gabungan k-Nearest Neighbor dan Algoritma Genetika (kNN-GA) yang digunakan untuk mengestimasi nilai missing. Algoritma genetika digunakan untuk melakukan optimasi nilai $k$ dan untuk melakukan seleksi variabel yang digunakan untuk estimasi nilai missingsehingga dapat menghasilkan nilai estimasi yang baik dengan Root Mean Square Error (RMSE) minimum. Hasil yang diperoleh menunjukkan bahwa metode imputasi kNN-GA dapat membantu dalam memperoleh nilai $k$ optimum dan dapat melakukan seleksi variabel dengan baik sehingga dapat meningkatkan akurasi kNN.
\end{abstract}

Kata Kunci :Algoritma Genetika, Imputasi, kNN, kNN-GA.

\begin{abstract}
Problems often arise in a data is incompleteness on a variable of the data or often called with missing data. Imputation is a method that can be used to handle missing data. One of simple imputation methods are k-Nearest Neighbor $(\mathrm{kNN})$. However, the weakness of $\mathrm{kNN}$ method is the problem in selecting the value of $k$, because a mistake in selecting the value of $k$ can degrade performance of kNN. This study examines the combined method k-Nearest Neighbor and Genetic Algorithm (kNN-GA) that are used to estimate missing values. Genetic algorithm is used to optimize the value of $k$ and for selecting the variables used to estimate missing values in order to produce a good estimation with minimum Root Mean Square Error (RMSE). The results show that the imputation method of kNN-GA can assist in obtaining the optimum value of $k$ and can do a good selection of variables so it can improve the accuracy of kNN.
\end{abstract}

Keywords :Genetic Algorithm, Imputation, kNN, kNN-GA.

\section{Pendahuluan}

Permasalahan yang sering muncul

pada suatu data adalah adanya

ketidaklengkapan data pada suatu variabel atau sering disebut dengan missing data. Adanya missing data menyebabkan kesulitan dalam melakukan analisis terhadap data tersebut karena analisis statistik hanya dapat diterapkan pada data yang lengkap.

Untuk menangani missing data, salah satu metode yang dapat digunakan adalah dengan mengestimasi nilai missing dengan suatu nilai tertentu yang 
dianggap sesuai, atau sering disebut dengan imputasi. Salah satu metode imputasi adalah metode $k$-Nearest Neighbor $(\mathrm{kNN})$. "Metode ini merupakan metode yang sederhana dan fleksibel karena dapat digunakan baik pada variabel dengan data kontinu maupun data diskrit (Batista dan Monard 2003)". "Pada penelitian yang dilakukan oleh Batista dan Monard (2003) yang menganalisa penggunaan $\mathrm{kNN}$ sebagai sebuah metode imputasi, dengan melakukan simulasi missing data sebanyak 10 hingga 60 persen dari total data menunjukkan bahwa metode imputasi $\mathrm{kNN}$ memberikan hasil yang sangat baik, bahkan pada saat data memiliki jumlah missing yang besar". "Jerez dan Molina (2010) juga membandingkan metode imputasi yang berbasiskan teknik statistik, yaitu mean, hot deck, multiple imputation dengan metode imputasi berbasiskan teknik machine learning, yaitu Multilayer Perceptron (MLP), Self Organizing Map (SOM), dan $\mathrm{kNN}$ pada data breast cancer. Hasilnya menunjukkan metode imputasi berbasis machine learning memiliki tingkat akurasi yang lebih tinggi daripada metode berbasis teknik statistik. Dan dari ketiga metode imputasi berbasis machine learning yang digunakan, metode $\mathrm{kNN}$ memberikan nilai prediksi yang paling baik karena menghasilkan nilai Mean Square Error yang paling kecil”.

Dalam beberapa penelitian, sebuah metode sering dikombinasikan dengan teknik optimasi untuk memperoleh hasil yang lebih optimal. "Salah satunya adalah penelitian Patil dan Bichkar (2010) yang mengintegrasikan decision tree learning dan algoritma genetika untuk menyusun decision tree yang optimal untuk mengestimasi nilai missing. Hasil penelitiannya menunjukkan bahwa algoritma yang diusulkan dapat meningkatkan akurasi estimasi nilai missing". "Siedlecky dan Sklansky (1989) juga mengkombinasikan K-Nearest Neighbor dan Algoritma Genetika, dimana algoritma genetika digunakan untuk melakukan seleksi variabel yang digunakan pada klasifikasi. Hasil penelitiannya menunjukkan bahwa metode tersebut dapat meningkatkan ketepatan klasifikasi. Selain itu, dalam penelitiannya juga menyatakan bahwa algoritma genetika merupakan alat yang powerfull dalam melakukan seleksi variabel terutama ketika demensi variabel yang digunakan cukup besar".

Salah satu kelemahan pada metode $\mathrm{kNN}$ adalah permasalahan dalam pemilihan nilai $k$ karena pemilihan nilai $k$ yang kurang tepat dapat menurunkan kinerja kNN. Penelitian ini bertujuan untuk mengatasi permasalahan missing 
data dengan teknik imputasi menggunakan gabungan kNN dan Algoritma Genetika (kNN-GA) dimana Algoritma Genetika digunakan untuk optimasi nilai $k$ pada $\mathrm{kNN}$ dan untuk melakukan seleksi variabel yang digunakan untuk mengestimasi nilai missing.

\section{Metode Penelitian}

\section{k-Nearest Neighbor $(\mathrm{kNN})$}

Algoritma $k$-Nearest Neighbor telah banyak digunakan untuk diiplementasikan dalam imputasi missing data terutama dalam dataset dengan missing data pada lebih dari satu variabel. Algoritma $\mathrm{kNN}$ menggunakan observasi yang mirip/serupa dengan observasi yang memiliki nilai missing. Sebuah observasi yang memuat satu atau lebih nilai missing yang akan diimputasi disebut sebagai observasi target. Berdasarkan pendekatan ini, ukuran jarak dihitung antara observasi target dengan tiap-tiap observasi lainnya. Jika $k$ merepresentasikan jumlah observasi yang mirip/serupa dengan observasi target, maka kemudian dipilih $k$ observasi yang memiliki jarak minimum dari observasi target.

Algoritma imputasi kNN adalah sebagai berikut :
1. Menentukan nilai $k$, yaitu jumlah observasi terdekat yang diinginkan.

2. Menghitung jarak euclidian antara observasi target dengan observasi yang tidak memuat nilai missing, dengan formula:

$$
d(\boldsymbol{x}, \boldsymbol{y})=\sqrt{\sum_{j=1}^{s}\left(x_{j}-y_{j}\right)^{2}}
$$

dimana:

$\boldsymbol{x}=$ vektor observasi target dengan variabel sebanyak $s$ variabel, $\boldsymbol{x}=$ $\left[x_{1}, x_{2}, \ldots, x_{s}\right]^{T}$

$\boldsymbol{y}=$ vektor observasi yang tidak memuat nilai missing dengan variabel sebanyak $s$ variabel, $\quad \boldsymbol{y}=$ $\left[y_{1}, y_{2}, \ldots, y_{s}\right]^{T}$

$d(\boldsymbol{x}, \boldsymbol{y})=$ jarak antara $\boldsymbol{x}$ dan $\boldsymbol{y}$

$x_{j}=$ nilai variabel ke- $j$ pada $\boldsymbol{x}$

$y_{j}=$ nilai variabel ke-j pada $\boldsymbol{y}$ $j=1,2, \ldots, s$.

3. Mencari $k$ observasi yang memiliki nilai $d(\boldsymbol{x}, \boldsymbol{y})$ minimum.

4. Melakukan imputasi missing data dengan menggunakan prosedur weighted mean imputation, dengan formula:

$$
\hat{x}_{j}=\frac{1}{W} \sum_{k=1}^{K} w_{k} y_{k j}
$$

dimana:

$\hat{x}_{j}=$ nilai imputasi

$y_{k j}=$ nilai variabel ke $j$ pada observasi ke- $k, k=1,2, \ldots, K$ 
$w_{k}=$ bobot observasi ke- $k, w_{k}=$

$1 / d\left(\boldsymbol{x}, \boldsymbol{y}_{k}\right)$

$W=\sum_{k=1}^{K} w_{k}$

\section{Algoritma Genetika}

Algoritma genetika merupakan algoritma untuk memecahkan suatu pencarian nilai dalam masalah optimasi dengan meniru proses genetik pada makhluk hidup. Algoritma genetika bekerja dengan mempertahankan sebuah populasi yang terdiri dari individuindividu, dimana tiap individu merepresentasikan sebuah solusi pada permasalahan yang dihadapi. Individu dikodekan dalam bentuk kromosom yang terdiri dari komponen genetik terkecil, yaitu gen. Dari individu yang ada, dihitung nilai fitness yang digunakan sebagai kriteria solusi terbaik.

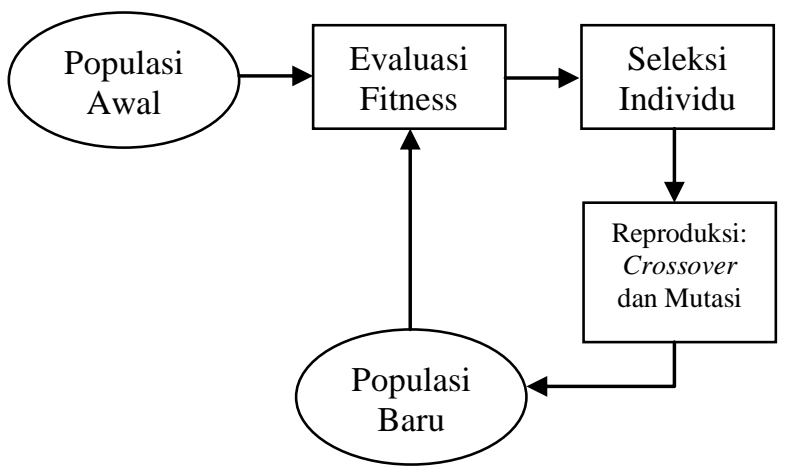

Gambar 1.Siklus Algoritma Genetika

Individu-individu yang lolos proses seleksi kemudian melakukan reproduksi dengan perkawinan silang (crossover) dan mutasi dengan probabilitas crossover $\left(P_{c}\right)$ dan probabilitas mutasi $\left(P_{m}\right)$ sehingga menghasilkan keturunan. Keturunanketurunan ini kemudian dievaluasi untuk membentuk populasi baru yang memiliki kriteria yang lebih baik. "Setelah beberapa generasi terbentuk, algoritma akan konvergen pada individu terbaik yang diharapkan merepresentasikan solusi optimal dari permasalahan yang dihadapi (Gen dan Cheng 1999)".

\section{kNN-GA}

Metode kNN-GA merupakan metode gabungan antara $\mathrm{kNN}$ dan Algoritma Genetika. Algoritma imputasi missing data dengan metode $\mathrm{kNN}$ GAadalah sebagai berikut:

1. Menentukan inisial populasi, meliputi jumlah gen dalam kromosom dan jumlah kromosom dalam individu.

2. Melakukan proses algoritma $\mathrm{kNN}$ untuk setiap kromosom dalam populasi. Setiap kromosom dikodekan menjadi nilai $k$ dan representasi variabel yang digunakan oleh kNN dalam melakukan imputasi. Kemudian menghitung RMSE dengan formula:

$$
R M S E=\sqrt{\frac{1}{n} \sum_{i=1}^{n}\left(y_{i}-\hat{y}_{i}\right)^{2}}
$$

dimana:

$n=$ jumlah observasi

$y_{i}=$ nilai aktual pada observasi ke- $i$

$\hat{y}_{i}=$ nilai estimasi pada observasi ke- $i$ 
3. Menghitung nilai fitness dari tiap kromosom dalam populasi dengan formula:

$$
f=\frac{1}{(R M S E+h)}
$$

dimana:

$h=$ nilai yang kecil $(0 \leq h \leq 1)$

4. Memilih kromosom berdasarkan nilai fitness.

5. Melakukan perkawinan silang (crossover) dan mutasi untuk mendapatkan keturunan (offspring)

6. Melakukan elitism dan replacement sehingga diperoleh populasi baru.

7. Kembali ke tahap nomor 2 hingga kriteria yang ditentukan terpenuhi.

\section{Metodologi}

Data yang digunakan pada penelitian ini adalah data vertebral column, seeds, dan computer hardware yang diambil dari UCI Machine Learning Repository yang merupakan data lengkap atau tidak terdapat nilai missing. Jumlah data dan jumlah variabel dari masingmasing dataset dapat dilihat pada Tabel 1 .

Tabel 1. Jumlah Data dan Jumlah

Variabel pada Dataset

\begin{tabular}{lcc}
\hline Dataset & $\begin{array}{c}\text { Jumlah } \\
\text { data }\end{array}$ & $\begin{array}{c}\text { Jumlah } \\
\text { variabel }\end{array}$ \\
\hline Vertebral column & 310 & 6 \\
Seeds & 210 & 7 \\
$\begin{array}{l}\text { Computer } \\
\text { hardware }\end{array}$ & 209 & 8 \\
\hline
\end{tabular}

Penelitian ini menggunakan data lengkap karena data aktual dan data hasil imputasi akan dibandingkan untuk mengukur kinerja metode kNN-GA. Langkah berikutnya adalah menghilangkan secara random beberapa nilai pada salah satu variabel pada masing-masing dataset untuk mendapatkan nilai missing sebanyak $10 \%$ dan $20 \%$ dari jumlah data. Kemudian dilakukan imputasi missing data dengan kNN-GA. Untuk mencari nilai $k$ optimum pada metode $\mathrm{kNN}-\mathrm{GA}$, nilai $k$ direpresentasikan dalam 4 gen biner. Sebagai contoh kromosom individu yang terbentuk untuk nilai $k=10$ adalah:

\begin{tabular}{|l|l|l|l|}
\hline 1 & 0 & 1 & 0 \\
\hline
\end{tabular}

Gambar 2. Kromosom Individu untuk

Nilai $k$

String biner selanjutnya merepresentasikan kromosom untuk seleksi variabel. Misalkan terdapat 5 variabel dalam dataset, maka sebuah vektor biner berukuran $5 \times 1$ yang berunsurkan nilai 1 dan 0 diartikan sebagai vektor indikator yang menunjukkan kode seleksi variabel, kode 1 menunjukkan variabel yang terpilih. Sebagai contoh kromosom individu yang terbentuk adalah:

\begin{tabular}{|l|l|l|l|l|}
\hline 1 & 1 & 0 & 1 & 1 \\
\hline
\end{tabular}

Gambar 3. Kromosom Individu untuk Variabel 
String tersebut akan dikodekan ke dalam metode $\mathrm{kNN}$ menjadi, variabel yang terpilih dalam proses imputasi dengan kNN adalah variabel ke-1, ke-2, ke-4, dan ke-5. Variabel ke-3 tidak terpilih karena berkode 0 .

Langkah-langkah metode $\mathrm{kNN}$ GA selanjutnya adalah sebagai berikut:

1. Membangkitkan secara random sebanyak 50 individu dalam populasi.

2. Menghitung nilai fitness untuk setiap individu dalam populasi sesuai dengan persamaan (4).

3. Membentuk individu baru dengan melakukan seleksi roullete wheel, crossover satu titik dengan probabilitas $\left(P_{c}\right)$ sebesar 0,8 dan mutasi dengan probabilitas $\left(P_{m}\right)$ sebesar 0,2. Kemudian melakukan elitism dan replacement sehingga diperoleh populasi baru.

4. Memilih individu terbaik dari populasi yang merupakan solusi terbaik setelah kriteria yang ditentukan terpenuhi, yaitu ketika mencapai generasi maksimum 50 generasi atau selisih nilai fitness terbaik dalam 5 generasi terakhir tidak lebih dari $1 \times 10^{-8}$.

\section{Hasil dan Pembahasan}

Sebelum melakukan proses imputasi, terlebih dahulu dilakukan eksplorasi data untuk mengetahui gambaran awal dari data yang digunakan. Pada penelitian ini, pola missing data yang digunakan adalah missing data univariat atau missing data hanya terjadi pada satu variabel, yaitu variabel yang menempati urutan terakhir pada masingmasing dataset. Statistik deskriptif dari variabel yang mengandung nilai missing dapat dilihat pada Tabel 2.

Tabel 2. Statistik Deskriptif dari Variabel yang mengandung Nilai Missing

\begin{tabular}{lcccc}
\hline \multicolumn{1}{c}{ Dataset } & $\begin{array}{c}\text { Urutan } \\
\text { Variabel }\end{array}$ & Mean & Min & Maks \\
\hline $\begin{array}{l}\text { Vertebral } \\
\text { column }\end{array}$ & Ke-6 & 26.30 & -11.06 & 418.54 \\
$\begin{array}{l}\text { Seeds } \\
\text { Computer }\end{array}$ & Ke-7 & 5.41 & 4.52 & 6.55 \\
hardware & Ke & 99.3 & 15.0 & 1238.0 \\
\hline
\end{tabular}

Untuk melakukan analisa hasil seleksi variabel pada metode kNN-GA, maka perlu dilihat korelasi antar variabel pada masing-masing dataset untuk mengetahui apakah hasil seleksi variabel pada metode $\mathrm{kNN}-\mathrm{GA}$ dipengaruhi oleh korelasi antar variabel atau tidak. Matriks korelasi dari masing-masing dataset adalah sebagai berikut:

Vertebral column

$$
\boldsymbol{\rho}=\left[\begin{array}{cccccc}
1 & & & & & \\
0.63 & 1 & & & & \\
0.72 & 0.43 & 1 & & & \\
0.82 & 0.06 & 0.59 & 1 & & \\
-0.25 & 0.03 & -0.08 & -0.34 & 1 & \\
0.64 & 0.39 & 0.53 & 0.52 & -0.03 & 1
\end{array}\right]
$$

Dari matriks korelasi tersebut diketahui bahwa terdapat tiga variabel yang mempunyai korelasi kuat dengan variabel ke-6 atau variabel yang mengandung nilai missing, yaitu variabel ke-1 $\left(\rho_{16}=0.64\right)$, variabel ke-3 $\left(\rho_{36}=\right.$ 
$0.53)$, dan variabel ke-4 $\left(\rho_{46}=0.52\right)$.

Sedangkan variabel ke-2 dan ke-5 tidak mempunyai korelasi yang kuat dengan variabel ke-6 karena memiliki nilai korelasi kurang dari 0.5 .

Seeds

$$
\boldsymbol{\rho}
$$

Pada data seeds, sebagian besar variabel memiliki korelasi yang kuat dengan variabel-ke-7 atau variabel yang mengandung nilai missing, yaitu variabel ke-1 $\left(\rho_{17}=0.86\right)$, variabel ke-2 $\left(\rho_{27}=\right.$ $0.86)$, variabel ke-4 $\left(\rho_{47}=0.93\right)$, dan variabel ke-5 $\left(\rho_{57}=0.75\right)$. Sedangkan variabel-ke-3 dan variabel ke-6 tidak mempunyai korelasi yang kuat dengan variabel ke-7.

Computer hardware

$$
\boldsymbol{\rho}=\left[\begin{array}{cccccccc}
1 & & & & & & & \\
-0.34 & 1 & & & & & & \\
-0.38 & 0.76 & 1 & & & & & \\
-0.32 & 0.54 & 0.54 & 1 & & & & \\
-0.30 & 0.52 & 0.56 & 0.58 & 1 & & \\
-0.25 & 0.27 & 0.53 & 0.49 & 0.55 & 1 & & \\
-0.31 & 0.79 & 0.86 & 0.66 & 0.61 & 0.61 & 1 & \\
-0.29 & 0.82 & 0.90 & 0.65 & 0.61 & 0.59 & 0.97 & 1
\end{array}\right]
$$

Hampir semua variabel pada data computer hardware juga mempunyai korelasi yang kuat dengan variabel ke-8 atau variabel yang mengandung nilai missing, yaitu variabel ke-2 $\left(\rho_{28}=0.82\right)$, variabel ke-3 $\left(\rho_{38}=0.90\right)$, variabel ke-4 $\left(\rho_{48}=0.65\right)$, variabel ke-5 $\left(\rho_{58}=0.61\right)$, variabel ke-6 $\left(\rho_{68}=0.59\right)$, dan variabel ke-7 $\left(\rho_{78}=0.97\right)$. Hanya variabel-ke-1 yang tidak mempunyai korelasi yang kuat dengan variabel ke-8 $\left(\rho_{18}=-0.29\right)$.

Langkah selanjutnya adalah melakukan imputasi missing data. Hasil imputasi missing data dengan kNN-GA pada data vertebral column, seeds, dan computer hardware dapat dilihat pada Tabel 3.

\begin{tabular}{|c|c|c|c|c|}
\hline Dataset & $\begin{array}{c}\% \\
\text { Mising } \\
\text { Data }\end{array}$ & $\begin{array}{c}\text { Seleksi } \\
\text { Variabel }\end{array}$ & $\begin{array}{c}\text { Nilai } \\
k\end{array}$ & RMSE \\
\hline \multirow{2}{*}{$\begin{array}{l}\text { Vertebral } \\
\text { column }\end{array}$} & $10 \%$ & 011101 & 2 & 13.762 \\
\hline & $20 \%$ & 11001 & 9 & 15.220 \\
\hline \multirow{2}{*}{ Seeds } & $10 \%$ & 000110 & 3 & 0.130 \\
\hline & $20 \%$ & 0111110 & 15 & 0.157 \\
\hline \multirow{2}{*}{$\begin{array}{l}\text { Computer } \\
\text { hardware }\end{array}$} & $10 \%$ & 01111110 & 2 & 4.389 \\
\hline & $20 \%$ & $\begin{array}{llllllll}0 & 1 & 1 & 1 & 0 & 0 & 0\end{array}$ & 10 & 10.598 \\
\hline
\end{tabular}

Tabel 3. Hasil Imputasi Missing Data dengan metode $\mathrm{kNN}-\mathrm{GA}$

Pada proporsi missing data sebesar $10 \%$, nilai $k$ optimum yang diperoleh pada data vertebral column adalah $k=2$ dengan hasil seleksi variabel ke-2, ke-3 dan ke-5 yang terpilih dalam proses imputasi kNN-GA. Pada data seeds nilai $k$ optimum yang diperoleh adalah $k=3$ dengan hasil seleksi variabel ke-4 dan ke-5 yang terpilih dalam proses imputasi kNN-GA. Sedangkan pada data computer hardware nilai $k$ optimumnya adalah $k=2$ dengan hasil seleksi variabel ke-2, ke-3, ke-4, ke-5 dan ke-6.

Perbedaaan proporsi missing data sebesar $10 \%$ dan $20 \%$ memberikan hasil 
yang cukup bervariasi pada masingmasing dataset. Hasil penelitian menunjukkan bahwa nilai $k$ optimum yang diperoleh berbanding lurus dengan proporsi missing data, yang artinya semakin banyak jumlah missing data maka nilai $k$ optimum yang dihasilkan juga semakin besar. Hasil seleksi variabel juga menunjukkan perbedaan antara proporsi missing data $10 \%$ dan $20 \%$.

Pada proporsi missing data sebesar 20\%, nilai $k$ optimum yang diperoleh pada data vertebral column adalah $k=9$ dengan hasil seleksi variabel ke-1, ke-2 dan ke-5 yang terpilih dalam proses imputasi $\mathrm{kNN}-\mathrm{GA}$. Pada data seeds nilai $k$ optimum yang diperoleh adalah $k=15$ dengan hasil seleksi variabel ke-2, ke-3, ke-4 dan ke-5 yang terpilih dalam proses imputasi $\mathrm{kNN}-\mathrm{GA}$. Sedangkan pada data computer hardware nilai $k$ optimumnya adalah $k=10$ dengan hasil seleksi variabel ke-2, ke-3, dan ke4.

Berdasarkan matriks korelasi, variabel yang memiliki korelasi kuat dengan variabel ke-6 atau variabel yang mengandung nilai missing pada data vertebral column adalah variabel ke-1, ke-3, dan ke-4. Pada proporsi missing data $10 \%$, hasil seleksi variabel adalah variabel ke-2, ke-3, dan ke-5. Jika dilihat nilai korelasinya, variabel ke-3 mempunyai korelasi kuat dengan variabel ke-6, akan tetapi variabel ke-2 dan ke-5 tidak mempunyai korelasi yang kuat dengan variabel ke-6. Selain variabel ke3, variabel ke-1 dan ke-4 juga mempunyai korelasi yang kuat dengan variabel ke-6, akan tetapi tidak terpilih dalam hasil seleksi variabel dengan metode $\mathrm{kNN}-\mathrm{GA}$.

Sedangkan pada data seeds, hasil seleksi variabel dengan metode $\mathrm{kNN}-\mathrm{GA}$ adalah variabel ke-4 dan ke-5. Jika dilihat dari nilai korelasinya, kedua variabel tersebut mempunyai korelasi yang kuat dengan variabel ke-7. Selain variabel ke4 dan ke-5, variabel ke-1 dan ke-2 juga mempunyai korelasi yang kuat dengan variabel ke-7, akan tetapi tidak terpilih dalam hasil seleksi variabel dengan metode $\mathrm{kNN}-\mathrm{GA}$.

Pada data computer hardware, hasil seleksi variabel adalah variabel ke 2, ke-3, ke-4, ke-5, dan ke-6. Jika dilihat nilai korelasinya, semua variabel hasil seleksi tersebut mempunyai korelasi yang kuat dengan variabel ke-8, namun variabel ke-7 yang juga mempunyai korelasi yang kuat dengan variabel ke-8 tidak terpilih dalam hasil seleksi variabel dengan metode kNN-GA.

Hasil seleksi variabel pada proporsi missing data $20 \%$ juga menunjukkan hasil yang random jika dilihat hubungannya dengan nilai korelasi variabel. Hal ini menunjukkan bahwa 
hasil seleksi variabel dengan metode kNN-GA tidak sepenuhnya dipengaruhi oleh besarnya nilai korelasi antar variabel dari dataset tersebut.

Nilai RMSE yang dihasilkan metode kNN-GA pada Tabel 3 menunjukkan nilai yang relatif kecil. Hal ini menjelaskan bahwa teknik optimasi Algoritma Genetika pada kNN-GA dapat meningkatkan kinerja metode $\mathrm{kNN}$ dengan melakukan seleksi variabel dan optimasi nilai $k$ dalam melakukan imputasi missing data. Nilai $k$ optimum dan seleksi variabel dapat dihasilkan secara otomatis tanpa harus melakukan uji coba secara manual satu persatu.

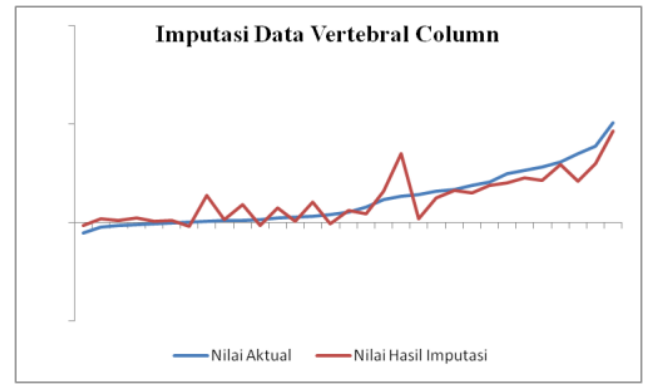

Gambar 4. Perbandingan Nilai Aktual dan Nilai Hasil Imputasi pada Data Vertebral Column

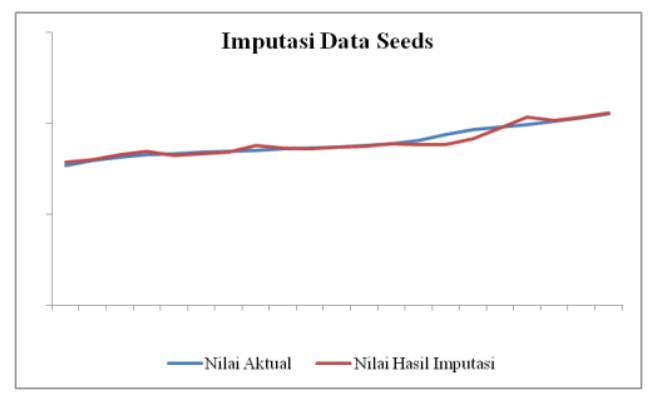

Gambar 5. Perbandingan Nilai Aktual dan Nilai Hasil Imputasi pada Data Seeds

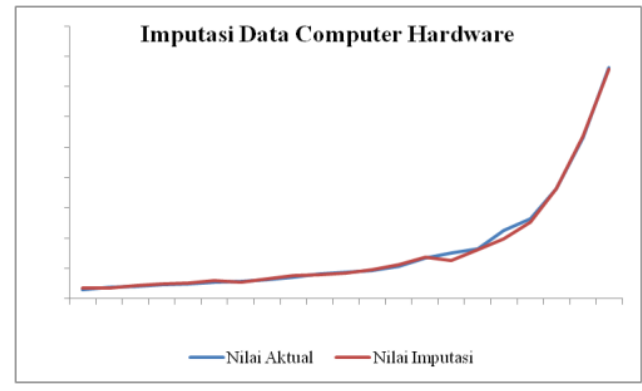

Gambar6. Perbandingan Nilai Aktual dan Nilai Hasil Imputasi pada Data Computer Hardware

Gambar 4, Gambar 5, dan Gambar 6 menunjukkan perbandingan nilai aktual dan nilai hasil imputasi pada data vertebral column, seeds, dan computer hardware dengan proporsi missing data $10 \%$. Dari gambar tersebut dapat dilihat bahwa secara umum metode kNN-GA dapat menghasilkan nilai imputasi yang mendekati nilai aktual.

\section{Kesimpulan}

Berdasarkan hasil penelitian yang telah dilakukan, dapat diambil kesimpulan sebagai berikut:

1. Metode imputasi kNN-GA dapat membantu dalam memperoleh nilai $k$ optimum. Hasil penelitian pada data vertebral column, seeds, dan computer hardware menunjukkan bahwa nilai $k$ optimum yang diperoleh berbanding lurus dengan jumlah missing data. 
2. Metode imputasi kNN-GA dapat melakukan seleksi variabel dengan baik sehingga dapat meningkatkan akurasi kNN. Hasil seleksi variabel yang diperoleh dengan metode $\mathrm{kNN}$ GA tidak sepenuhnya dipengaruhi oleh besarnya nilai korelasi antar variabel pada dataset.

\section{Pustaka}

Analoui, M. dan Amiri, M.F., 2006, "Feature Reduction of Nearest Neigbor Classifier using Genetic Algorithm", World Academy of Science, Engineering and Technology17, 36-39.

Batista G. dan Monard M.C., 2003, A Study of K-Nearest Neighbour as an Imputation Method, Working Paper, University Sao Paulo, Brazil.

Gen, M. dan Cheng, R., 1999, Genetic Algorithm and Optimization Engineering, John Wiley \& Sons, Inc, Japan.
Jerez, J.M., dan Molina, I., 2010, "Missing Data Imputation Using Statistical And Machine Learning Methods In A Real Breast Cancer Problem", Artificial Intelligence in Medicine50, 105-115.

Little, R.J., dan Rubin, D.B., 1987, Statistical Analysis with Missing Data, John Wiley \& Sons, Inc, New York.

Patil, D.V. dan Bichkar, R.S., 2010, "Multiple Imputation of Missing Data with Genetic Algorithm based Techniques", Evolutionary Computation for Optimization Techniques, hal. 74-78.

Siedlecki,W. dan Sklansky, J., 1989, "A Note on Genetic Algorithms for Large-Scale Feature Selection", Pattern Recognition Letters10, 335-347.

Wasito, I. dan Mirkin, B., 2005, "Nearest Neighbor Approach in the Least Square Data Imputation Algorithms", Information Sciences169, 1-25. 